Valéria Salek Ruiz

André Luis Lima de Araujo ${ }^{2}$

\section{Saúde e segurança e a subjetividade no trabalho: os riscos psicossociais}

\author{
Health and safety, and subjectivity at work: The psychosocial risks
}

${ }^{1}$ Psicóloga. Doutoranda do Programa de Pós-Graduação em Psicologia Social da Universidade do Rio de Janeiro, Rio de Janeiro, RJ, Brasil.

${ }^{2}$ Psicólogo, autônomo, Rio de Janeiro, RJ, Brasil.

Contato;

Valéria Salek Ruiz

Avenida Almirante Barroso, 81 $23^{\circ}$ andar, Rio de Janeiro, RJ, Brasil.

CEP: 20031-004

E-mail:

val.ruiz@hotmail.com

Os autores declaram que este trabalho não foi apresentado em reunião científica, não foi subvencionado e que não existem conflitos de interesses.

\section{Resumo}

Este ensaio apresenta reflexões sobre saúde e segurança no trabalho destacando as recentes propostas de inclusão dos aspectos psicossociais nas abordagens dos riscos ocupacionais que tradicionalmente valorizam apenas os aspectos objetivos (químicos, físicos e biológicos). Para subsidiar as colocações aqui mencionadas, foram utilizados referenciais teórico-metodológicos que, adotando uma perspectiva dinâmica, partem da atividade, do trabalho real, especialmente a psicodinâmica do trabalho e a perspectiva ergológica. Aponta-se para a necessidade de revisitar os atuais modelos de gestão de riscos ocupacionais centrados no controle e no cumprimento fiel das orientações, incorporando também as dimensões subjetivas, aquilo que é da ordem do não antecipável, que advém das situações reais com suas dramáticas, encontros, escolhas e ressingularizações. Nesse sentido, ressaltada a dimensão gestionária das atividades, seus protagonistas são convocados não apenas a cumprir prescrições elaboradas por especialistas, mas também a exercer, individual e coletivamente, a coautoria na gestão de sua saúde, segurança, trabalho e vida.

Palavras-chave: saúde; trabalho; riscos ocupacionais; aspectos psicossociais.

\begin{abstract}
This paper presents reflections on health and safety at work, highlighting the recent proposals that are for the inclusion of psychosocial aspects in the management of occupational risks, which traditionally dealt only with objective (chemical, physical, and biological) aspects. To support the arguments presented, we worked within theoretical and methodological frameworks that, by adopting a dynamic perspective, focused on activity, on actual work, especially the psychodynamics of work and the ergological perspective. We pointed at the need to revisit the current occupational risk management models centered in control and compliance of the given orientations, by also incorporating those subjective dimensions that cannot be foreseen, but were generated in real situations and include dramas, encounters, choices, and re-singularizing. Therefore, after the managerial dimension of the activities was revealed, their protagonists are summoned not only to comply with experts' prescriptions, but also to act as co-authors, individually and collectively, of the management of their own health, safety, work, and life.
\end{abstract}

Keywords: health; work; occupational risks; psychosocial aspects. 


\section{Introdução}

Procura-se com o presente ensaio insinuar pistas para exploração do campo conhecido como saúde e segurança no trabalho - SST. Como questão disparadora toma-se o desafio de incluir os aspectos subjetivos nos atuais modelos de gestão dos riscos ocupacionais que tradicionalmente privilegiam os aspectos objetivos.

As práticas desenvolvidas nesse campo organizam-se de modo geral em torno de dois grandes objetivos: atendimento às legislações vigentes e prevenção dos acidentes e das doenças de trabalho. Buscam antecipar-se aos perigos, identificando e eliminando os riscos ou, antes, mantendo-os sob controle. Para tal antecipação, consideram-se alguns cenários e conceitos (homem, trabalho, risco, saúde) genéricos e hipotéticos. Tais práticas enfatizam a prescrição de comportamentos e procedimentos considerados saudáveis e seguros. Os conhecimentos que dão base a essas prescrições - geralmente elaboradas por especialistas - são apresentados como superiores aos "saberes do senso comum" ou aos oriundos da experiência e devem ser fielmente seguidos pelos trabalhadores.

As medidas normalizadoras ou prescritivas, de reconhecimento e controle dos perigos já sabidos, são consideradas relevantes, podendo-se dizer que sejam pontos de partida para a contínua melhoria das condições de saúde e segurança no trabalho. Essas medidas, entretanto, não são suficientes para abordar os riscos não "objetiváveis", os ainda não conhecidos, os imprevistos, os fatores psicossociais, enfim, as dimensões imateriais do trabalho. Alguns riscos podem decorrer da tentativa de simplificação do que está envolvido na atividade de trabalho. As generalizações têm como premissa e presunção a redução da complexidade e variabilidade do humano e do trabalho; as fórmulas daí advindas jamais são capazes de contemplar todas as possíveis manifestações no trabalho, pois nem todos os acontecimentos e riscos são antecipáveis, controláveis ou elimináveis, seja no âmbito do trabalho ou naquele da vida. A ênfase exclusiva nas medidas normalizadoras (em geral denominadas normativas) e na chamada gestão por indicadores diz respeito ao risco de fomentar o mascaramento dos problemas reais, bem como à burocratização excessiva, algo que pode tornar-se um fim em si e se autoafirmar.

As práticas em SST costumam partir de uma análise estática do posto de trabalho, muitas vezes sem contemplar a complexidade e a dinâmica que envolvem as situações reais de trabalho. Desconsideram a defasagem entre o trabalho prescrito e o real, bem como o saber oriundo da experiência. Grande parte das medidas prescritivas é determinada por técnicos especializados, abrangendo ainda pouca ou nenhuma participação dos trabalhadores efetivamente envolvidos nas tarefas.

A tradição de abordar questões relacionadas à higiene, segurança e saúde no trabalho (HSST) de forma "preventivista" e "prescritivista" - com um tipo de ênfase na prescrição como se tivesse chegado à verdade final do trabalho, a ser fielmente repetida pelos trabalhadores, cuja participação limita-se ao exercício dessa fidelidade, minuciosamente controlada - não é observada apenas no Brasil. Cenário similar é relatado por Vasconcelos e Lacomblez (2004, p. 162) em Portugal:

Tradicionalmente, as questóes relacionadas com a HSST têm vindo a ser, de regra geral, exclusivamente tratadas com base em regulamentos e procedimentos minuciosamente prescritos por especialistas na matéria e cujo cumprimento é necessário garantir e controlar. (VASCONCELOS; LACOMBLEZ, 2004, p. 162)

Nessa mesma linha, grande quantidade dos estudos e intervenções em SST persegue dados objetivos e parte da antecipação de cenários possíveis da previsibilidade dos fenômenos e comportamentos (baseando-se no estabelecimento mediano do "normal”) para formulação de normas e procedimentos.

A partir desta breve apresentação, procura-se neste ensaio revisitar algumas das ideias fundantes dos atuais modelos de gestão dos riscos ocupacionais, incorporando as contribuições de autores que privilegiam a perspectiva dinâmica, o ponto de vista da atividade, o trabalho real e o diálogo entre os diferentes saberes sob a mediação de uma perspectiva ética. Dentre os referenciais privilegiados destacam-se aqui as abordagens chamadas de "clínicas do trabalho"3 que têm apostado na atividade como referência privilegiada para romper com visões distanciadas dos especialistas e fazer aproximações entre os debates sobre saúde, segurança, produtividade e qualidade. Ou seja, essas abordagens partem das sinalizações da ergonomia que, ao se deslocar do laboratório experimental e aproximar-se do trabalho real, destacou a defasagem existente entre o trabalho prescrito e aquele de fato realizado, ou seja, a atividade de trabalho. Assim, tenta-se desviar da tradição no campo, de busca de objetividade e controle, procura-se aqui observar as relações dinâmicas estabelecidas entre saúde, trabalho e subjetividade. Para tanto, recorremos a referenciais teórico-metodológicos compatíveis.

\footnotetext{
${ }^{3}$ Refere-se ao conjunto de teorias ou abordagens, que, embora com divergências de ordem teórica, epistemológica e metodológicas, possuem noções-chave que as caracterizam e as aproximam, especialmente, a situação do trabalho, as relações entre sujeito, trabalho e meio. Ver: Bendassolli; Soboll, 2011.
} 


\section{Breve apresentação dos principais modos de gestão em SST}

Alguns autores têm olhado com atenção para os efeitos produzidos por certos modos de gestão em SST. Chanlat (2002, p. 119) define "modo" ou "método de gestão" como o conjunto de práticas administrativas colocadas em execução pela direção de uma empresa, para atingir os objetivos que ela tenha fixado, estabelecendo as condições, a organização do trabalho, a natureza das relações hierárquicas, os sistemas de avaliação e controle dos resultados, as políticas para gestão de pessoas e valores, etc.

Tais modos, em geral, não são dissociados de seu conjunto de práticas, dos valores éticos disseminados e das políticas de "recursos humanos" adotados. Como desdobramento das análises, tem-se um alerta sobre o quanto a priorização de uma gestão exclusivamente sensível ao controle normativo, a indicadores e a certificações poderia estimular um mascaramento e o afastamento dos problemas reais do cotidiano de trabalho e levar à burocratização excessiva.

Resultados e indicadores que são previamente estabelecidos, desdobrados e assumidos através de metas de desempenho setorial ou individual têm impactos financeiros, emocionais e, quando não atingidos, até mesmo na projeção ou ascensão na carreira:

Propor um controle a partir de normas, como os ISO 2000, ISO 9000, ISO 13000, não passa de invocação mágica. À sombra dessas garantias publicitárias, esconde-se inevitavelmente uma intensa atividade de evitamento, de artimanha e, evidentemente, de fraude, como ocorre na presença de toda prescrição, como já tentei explicar. E quanto mais arrogantes forem os objetivos declarados, mais numerosas e graves serão as fraudes. (DEJOURS, 2008, p. 69)

Chanlat (2002, p. 120) denomina "tecnoburocrático" o modo de gestão da SST que privilegia o controle e a submissão do humano ao "império da norma" heterodeterminada e aos especialistas técnicos. $\mathrm{O}$ autor descreve ainda outros três modos possíveis de gestão da SST, os "métodos de gestão tayloriano e neotaylorianos", o método "com base na excelência" e o "de gestão participativa".

O primeiro modo, inspirado em Taylor, caracteriza-se pela extrema divisão do trabalho e pela ideia de que pessoas são dotadas de energia física e muscular, movidas essencialmente por motivações de ordem econômica, força de trabalho. Esse modelo remete a um universo apoiado em cálculos e busca de controle dos processos de trabalho. O método "com base na excelência”, difundido no início dos anos 80, seria uma resposta ocidental ao desafio da administração japonesa, fundamentada na qualidade. Nesse modo, o líder passa a ser figura supervalorizada, e o ser humano é consagrado aos desafios e à superação. No que se refere à SST, um dos efeitos associados a esse método é o incentivo a um superinvestimento no trabalho, um reforço da imagem de invulnerabilidade e da negação dos riscos de acidentes e doenças. Esgotamento, problemas cardiovasculares e até suicídios têm sido correlacionados a esse modelo.

Por fim, Chanlat (2002) aponta o método de gestão participativa como o que lhe parece mais promissor e salutar por valorizar a participação e a troca de experiências. Uma de suas principais características é o princípio de que as pessoas são responsáveis, devendo ter autonomia na realização de suas tarefas.

Segundo esse autor, os modelos de gestão não são imutáveis, mas passíveis de transformação, para o que, entretanto, torna-se fundamental introduzir e/ ou valorizar cooperação, confiança, reconhecimento, solidariedade e diálogo com a adoção de políticas e práticas que favoreçam a criação de espaço para a palavra em todos os níveis. Outro ingrediente básico é buscar sempre a coerência entre o método de gestão prescrito e as práticas e os modos reais de gestão.

Assim como Dejours (2008) e Chanlat (2002), outras abordagens que relacionam trabalho e subjetividade têm apostado na atividade como referência privilegiada para romper com visões especialistas fragmentadas e aproximar os debates sobre saúde, segurança, produtividade e qualidade. Dentre as noções-chave que caracterizam essas teorias destaca-se a preponderância de se aproximar do trabalho para considerar a atividade real e não apenas o trabalho pensado hipoteticamente.

\section{Os enigmáticos aspectos psicossociais}

Recentemente alguns documentos nacionais e internacionais têm mencionado a importância da inclusão dos aspectos ou fatores psicossociais nas análises de riscos, que tradicionalmente contemplam apenas aspectos objetivos (químicos, físicos e biológicos). Citemos alguns desses documentos que fazem alusão sobretudo a "eventos", "fatores" ou "situações" adversas que podem causar danos, colocar em perigo a saúde e a segurança do trabalhador ou causar impacto na produção.

A Organização Internacional do Trabalho - OIT, desde 1984, refere-se aos fatores psicossociais no trabalho como a interação entre o trabalho (ambiente, satisfação e condições de sua organização) e as capacidades do trabalhador (necessidades, cultura, sua situação externa ao trabalho). De um lado, portanto, está a inter-relação entre conteúdo, organização e gerenciamento do trabalho, entre outras condições ambientais e organizacionais, e, do outro, as compe- 
tências e necessidades dos empregados. Com base nas definições da OIT, Glina (2010, p. 15) apresenta definição que considera satisfatória de riscos psicossociais: "aspectos do desenho do trabalho, organização e gerenciamento do trabalho e seus contextos sociais e ambientais, que têm o potencial de motivar danos psicológicos e sociais ou físicos”.

Em recente publicação da OIT (ORGANIZAÇÃO INTERNACIONAL DO TRABALHO, 2010) sobre os riscos emergentes e novos modelos de prevenção, os fatores psicossociais e o estresse relacionado com a atividade laboral são destacados dentre os riscos emergentes e relacionados com as novas características dos mundos do trabalho.

Na legislação brasileira, a Norma Técnica sobre Lesões por Esforços Repetitivos ou Distúrbios Osteomusculares Relacionados ao Trabalho publicada pelo Instituto Nacional de Seguro Social (2003) descreve os fatores psicossociais como percepções subjetivas que o trabalhador tem dos fatores da organização do trabalho.

A Norma Regulamentadora 33 - Segurança e Saúde para os Trabalhos em Espaço Confinado do Ministério do Trabalho e Emprego (BRASIL, 2006) - também chama atenção para os "fatores de riscos psicossociais", atrelando-os, embora de forma ainda imprecisa, ao exame médico ocupacional:

Todo trabalhador designado para trabalhos em espaços confinados deve ser submetido a exames médicos específicos para a função que irá desempenhar, conforme estabelecem as NRs 07 e 31, incluindo os fatores de riscos psicossociais com a emissão do respectivo Atestado de Saúde Ocupacional - ASO. (BRASIL, 2006, p. 3)

A indicação normativa que, conforme afirmamos, é bastante valorizada no campo da SST, ao sinalizar a inclusão dos enigmáticos riscos psicossociais, abre positivo debate em diversos aspectos, principalmente por forçar aproximação de temas e problemas que costumavam (ou costumam) ser tratados de forma segmentada e especializada.

Se, por um lado, a menção nos documentos tem provocado abertura para discussão e pode estimular ações e oportunidade de novos campos de pesquisas, por outro, algumas linhas de interpretação têm procurado atender objetivamente às novas exigências. No caso da NR 33, por exemplo, os entendimentos do que seja a nova demanda têm-se desdobrado, sugerindo a adição de avaliações psicológicas ou de contexto social ao tradicional exame médico ocupacional. Em tais casos, cada especialista contribuiria para avaliar seu domínio específico, pouco modificando, assim, a visão fragmentada de saúde como objeto de especialistas e mantendo o foco da avaliação no indivíduo ou no ambiente, subestimando a relação com o trabalho.

Olhar para o psíquico, para o social, para o indivíduo e para o ambiente é radicalmente diferente de olhar para o que é colocado em ação, produzido nas e pelas situações de trabalho - algo que nos leva a ultrapassar as totalidades, individualidades e ambientes, e remete necessariamente ao que se passa no trabalho. Na literatura pesquisada, considera-se existir "consenso razoável” (GLINA, 2010, p. 17) entre os especialistas sobre quais seriam os fatores psicossociais no trabalho com potencial para dano. A maior parte das definições faz referência ao contexto ou ao conteúdo do trabalho e ressalta que se trata de uma interação, ou seja, essas definições oficiais, no mínimo, levariam, ou deveriam levar, a ultrapassar o foco nas individualidades, nos ambientes, remetendo necessariamente ao que se passa no trabalho (real).

Embora ainda não haja clareza para afirmação taxativa sobre suas consequências, a demanda de inclusão de aspectos psicossociais, trazida pelos documentos citados, aponta três relevantes questões: incluir aspectos subjetivos na gestão de riscos ocupacionais que tradicionalmente privilegiam aspectos objetivos (químicos, físicos e biológicos); ampliar o conceito de saúde para além da visão biomédica de saúde entendida como sinônimo de "ausência de doença”; e valorizar a percepção dos trabalhadores nas análises de riscos à saúde e à segurança no trabalho, o que implica também reposicionamento do especialista nesse processo de avaliação e gestão da saúde.

Para entender e melhor contextualizar essas propostas e questões faz-se necessário um rápido sobrevoo sobre esse campo da saúde e trabalho, no qual convivem ideias oriundas da medicina do trabalho, higiene e saúde ocupacional, promoção da saúde e da saúde do trabalhador.

\section{Do modelo biomédico para a saúde integral: o diálogo entre os saberes}

Antes de abordar a relação saúde/trabalho é importante esclarecer o que se entende como saúde. Concordando com Caponi (2003), observa-se que, nas práticas cotidianas, a visão hegemônica de saúde é entendida como sinônimo de funcionamento normal ou ausência de doença. Essa visão, ainda corrente, é a que está na base das formações profissionais e fundamenta estruturação dos serviços e intervenções efetivas nos corpos. "Ainda hoje, esta associação entre a saúde e a normalidade parece ser a base de sustentação daquela que poderíamos considerar a definição mais corriqueira e, sem dúvida, a mais utilizada pelos profissionais da área de 
saúde" (CAPONI, 2003, p. 56). Seguindo essa lógica, a saúde também é considerada assunto da competência de especialistas que seriam os principais responsáveis pela avaliação técnica e prescrição da solução correta para os problemas.

Esta concepção restrita parece estar em contradição com a anunciada há décadas, desde 1948 pela Organização Mundial de Saúde, ratificada no Brasil e no exterior, que propõe uma visão integral de saúde como estado de completo bem-estar físico, psicológico e social, e não mera ausência de doenças.

O bem-estar significa a saúde no sentido mais amplo de maneira mais ativa. A nova noção torna-se partilhada, é promovida internacionalmente, acolhida pela legislação de diferentes países no mundo inteiro. (MAGGI, 2006)

Essa definição ampliada, por seus termos positivos muda também o restrito objetivo de curar as doenças para outro, mais amplo, o de promover a saúde integral. Ao incluir as dimensões psicológicas, sociais e políticas na concepção de saúde, demanda-se também a intervenção de outros saberes e profissionais.

No campo do trabalho, como resposta ao crescimento das insatisfações dos trabalhadores e empregadores no pós-guerra, a atuação médica voltada exclusivamente para os trabalhadores estende-se às intervenções sobre o ambiente. Nesse sentido, a medicina do trabalho é complementada com a saúde e a higiene ocupacional, que têm entre as principais finalidades controlar os riscos ocupacionais e intervir nos locais de trabalho. Mendes e Dias (1991) formulam algumas explicações possíveis para entender as dificuldades de concretização das propostas da saúde ocupacional, entre elas a desarticulação das atividades e as lutas coorporativas (que dificultam a concretização da interdisciplinaridade e a manutenção da abordagem aos trabalhadores como "objeto das ações” em saúde). Por fim, outra linha também constitutiva desse cenário configura-se a partir da saúde coletiva, da saúde do trabalhador, campo que tem por objeto o processo de saúde e doença dos grupos humanos em sua relação com o trabalho. A explicação para o adoecer já não se concentraria mais nas características dos indivíduos ou nos ambientes isoladamente, mas procuraria focalizar a relação entre eles, acionada pelo processo de trabalho. Nessa perspectiva, o saber dos trabalhadores passa a ser mais valorizado nas análises e produções de conhecimentos sobre saúde e trabalho.

No Brasil, o campo da saúde do trabalhador foi fortemente influenciado pelo movimento italiano dos trabalhadores pela saúde nas décadas de 1960 e 1970, conhecido como Modelo Operário Italiano de Luta pela Saúde (MOI). Dentre os frutos dessa heran- ça, destacam-se os princípios de interdisciplinaridade e da participação e o instrumento mapa de riscos, que foi incluído nas Normas Regulamentadoras de Segurança e Medicina do Trabalho. Segundo Brito (2004), tem-se aí a configuração de outra noção de saúde, que difere da anterior concepção de causalidade, seja de um agente específico ou de fatores. A saúde passa a ser vinculada ao processo de trabalho, vista como conquista permanente.

\begin{abstract}
Nesse sentido, o combate aos danos à saúde se dá principalmente por mudanças no processo de trabalho e também nas relações sociais que o envolvem. Isso implica a necessidade de conhecer o trabalho, como ele é realizado e sob quais relações sociais, para que os danos à saúde sejam interpretados e combatidos, mediante mudanças no processo de trabalho e também nas relações sociais que o envolvem. (BRITO, 2004, p. 93)
\end{abstract}

Fato é que, apesar do surgimento de questionamentos, do anúncio de novas concepções e exigências, observa-se que não se trata de uma sucessão ou substituição de modelos, mas da coexistência dos tradicionais modelos da medicina do trabalho, da saúde ocupacional, da higiene ocupacional, da saúde do trabalhador e da promoção de saúde. Trata-se de um campo em que coexistem paradigmas, concepções e interesses variados, muitas vezes conflitantes entre si, com predomínio das ideias oriundas do tradicional modelo biomédico de saúde.

Ao ser formulado como prática que se vê convocada a operar já não mais exclusivamente nos marcos da medicina, mas nos de várias profissões, informadas por um conjunto cada vez mais amplo de disciplinas, surge a obrigação de se refletir sobre as possíveis maneiras de pensar as relações entre esses diferentes campos disciplinares. Rodrigues (1998) propõe três possibilidades: multidisciplinar, interdisciplinar e transversalizadora ou desdisciplinar. Na primeira perspectiva, multidisciplinar, as diferentes disciplinas somariam seus olhares distintos na direção de um determinado objeto que, de natureza multifacetada, seria alvo da razão e do sujeito do conhecimento. Baseado nessa perspectiva multidisciplinar retoma-se à proposta, anteriormente sinalizada, da soma de avaliações especializadas em resposta à demanda de inclusão dos aspectos psicossociais. Pode-se questionar a suposição, que toma como base a lógica matemática, de que a soma de visões e avaliações fragmentadas poderia resultar em avaliação mais abrangente. Na verdade, trata-se de uma tradição de lógica que não se restringe ao campo da SST. O modelo moderno de racionalidade, desenvolvido no Ocidente a partir do século XVI, privilegiou ao longo de sua história a quantificação em detrimento das qualidades intrínsecas do objeto. Segundo Santos (2001), o privilégio da matemática na ciência moderna tem duas importantes consequ- 
ências. Em primeiro lugar, o privilégio da quantificação em detrimento das qualidades intrínsecas do objeto. Conhecer passa a significar quantificar, e o rigor científico passa a ser aferido pelo rigor das medições. Em segundo, a redução da complexidade; a ideia que se afirma é dividir e classificar para facilitar e possibilitar a compreensão por partes.

Na segunda perspectiva, a interdisciplinar, as diversas disciplinas lançariam seus olhares para um dado objeto, podendo produzir interdisciplinas a partir do cruzamento dessas diferentes visões. Nessas duas perspectivas observa-se esforço de flexibilização das fronteiras das disciplinas, mas ambas mantêm a ideia de objeto e sujeito do conhecimento que estariam dados a priori. Por fim, na perspectiva desdisciplinar ou transversalizante, práticas e discursos, ao focar os objetos construídos historicamente, podem vir a construir outros, novos, e romper com determinados domínios instituídos de competência. Nesse encontro não haveria uma essência de identidade a ser preservada, mas a abertura para a possibilidade de criação de novos domínios, sujeitos do conhecimento e objetos.

Para pensar a saúde como algo além de objeto de conhecimento e intervenção das diversas disciplinas, serão exploradas algumas das contribuições de Georges Canguilhem que possibilitam avanços em direção a referenciais epistemológicos mais compatíveis com as dinâmicas das relações estabelecida entre humanos, meio e trabalho.

\section{Saúde e criação de normas: contribuições de Georges Canguilhem}

De acordo com a perspectiva de Canguilhem (1990), antes de se constituir como conceito científico, a saúde deve ser entendida como assunto que diz respeito a todos, a cada um(a) que a experimenta. Não se trata, portanto, da expressão de um valor universal, algo definido por especialistas e a eles restrito, mas antes relacionado a experiências singulares. Essa ideia é fundamental para o que se está abordando e remete a uma premissa de humildade epistemológica que delimita o lugar do especialista, evitando totalizações, com a respectiva e necessária relativização dos conhecimentos. A saúde, segundo o autor, pode ser pensada como margem de tolerância às infidelidades do meio. Desse modo, o distúrbio, o erro, o fracasso fazem parte da vida, e a saúde seria a própria expressão da normatividade, um movimento ativo de criação de novas normas e, sendo assim, jamais poderia ser reduzida a fenômeno meramente adaptativo.

O ser vivo qualificado vive como organismo independente, mas sempre em relação, em um mundo de objetos também qualificados e de acidentes possíveis.
É nisso que o meio é infiel. Sua infidelidade é exatamente seu devir, sua história. A vida não é, portanto, para o indivíduo, um movimento retilíneo; ela ignora a rigidez geométrica, ela é debate ou explicação com um meio em que há fugas, vazios esquivamentos e resistências inesperadas. (CANGUILHEM, 1990, p. 159)

O homem, assim como todos os viventes, é um ser ativo, capaz de variação e sempre escapa às medidas. Essa perspectiva torna-se incompatível com a ideia de homem passivo, executante fiel, o tradicional "paciente", pensado, descrito e objeto de intervenções de especialistas, alguém supostamente genérico e pronto para se encaixar e seguir fielmente alguma prescrição também genérica. O humano (e sua saúde), nessa perspectiva, não apenas se submete, sofre os impactos e influências, mas, principalmente, tem como importante característica sua atividade, sua capacidade de ação, de criar e recriar seu meio, de ser normativo, recentrando o meio heterodeterminado como seu, mesmo que parcialmente ou no infinitesimal. Nessa perspectiva, pode-se avançar na fundamentação e no redirecionamento de práticas em SST, especialmente no que diz respeito ao reposicionamento do especialista em sua relação com os conhecimentos e com a prescrição.

\section{O trabalho e o debate de normas}

Partindo das ideias de Canguilhem (1990), a ergologia avança em algumas reflexões, trazendo-as para o campo do trabalho. Essa perspectiva não se pretende uma nova disciplina, mas uma démarche, para compreender/transformar o trabalho, tomando como referencial o ponto de vista da atividade, a defasagem apontada pela ergonomia da atividade entre trabalho prescrito e trabalho real. Propõe o estabelecimento de uma análise dinâmica, que contemple as dimensões micro e macro sempre contidas em uma situação de trabalho, na atividade (SCHWARTZ; DURRIVE, 2007).

A defasagem entre o trabalho real e o prescrito tem sido objeto de interesse de diversos autores que pensam o campo do trabalho, em especial o da ergonomia da atividade (DANIELLOU, 2004; WISNER, 1994; CLOT, 2006). Brito (2009) vincula o esforço conceitual sinalizado na expressão "trabalho real" ao pressuposto de que as prescrições são recursos incompletos. Nesse sentido, as pessoas são protagonistas ativos do processo produtivo, e, assim, mesmo nas tarefas mais repetitivas, o trabalho nunca é mera execução.

O conceito de trabalho prescrito, em linhas gerais, refere-se a um conjunto de condições e exigências:

O trabalho prescrito inclui, portanto dois componentes básicos: as condições determinadas de uma situação de trabalho (as características do dispositivo técnico, o ambiente físico, a matéria-prima utilizada, as condições socioeconômicas etc.) e as prescrições (normas, ordens, procedimentos, resultados a serem obtidos etc.). (TELLES; ALVAREZ, 2004, p. 67) 
A ergonomia, ao aproximar-se do trabalho real, destacou a defasagem existente entre o trabalho prescrito e aquele de fato realizado, ou seja, a atividade de trabalho. Essa ideia central na abordagem de ergonomia tem sido inspiradora de importantes reflexões e debates. Nessa área do saber, muitas vezes, é utilizada a expressão normas antecedentes para designar os aspectos tradicionalmente referidos pela ergonomia como trabalho prescrito. Ainda segundo as autoras citadas acima, embora não exista diferença de natureza entre as duas concepções, a noção de normas antecedentes seria mais abrangente, posto que incluiria as normas históricas e sociais e indicaria a presença de valores do "bem comum".

Os valores são sempre objeto de debates, conflitos e arbitragens. Isso reforça a ideia de que o trabalho executado nunca é mera fiel execução da prescrição: mesmo quando supostamente assim se apresenta, ele é necessariamente atravessado por variabilidades e imprevistos e convoca o protagonista a fazer escolhas. Assim como na vida, depara-se constantemente com exigências múltiplas, com situações em que são necessárias priorizações, atribuição de valores e negociações de compromissos.

Nesse sentido, viver/trabalhar é gerir, pois as “dimensões gestionárias” estão presentes em toda atividade de trabalho realizada, até naquelas aparentemente repetitivas. Sempre existirá margem de manobra, por menor que seja; portanto, como qualquer atividade humana, a gestão não é neutra, supondo sempre escolhas e hierarquização de valores:

A gestão, como verdadeiro problema humano, advém por toda parte onde há variabilidade, história, onde é necessário dar conta de algo sem poder recorrer a procedimentos estereotipados. Toda gestão supõe escolhas, arbitragens, uma hierarquização de atos objetivos, portanto de valores em nome dos quais essas decisões se elaboram. (SCHWARTZ, 2004, p. 23)

Assim, Schwartz (2004) chama a atenção para essa dimensão gestionária de qualquer atividade, algo geralmente ocultado; isso ressaltado, é possível desviar-se desse modo que hegemonicamente apresenta a gestão como tarefa destinada a especialistas para tanto habilitados.

Na busca de maior controle da produção e aumento das margens de lucro, o que se passou a denominar "gestão" passou a ocupar lugar de crescente destaque em nossa sociedade. Nesse movimento, o foco das atenções foi deslocado, afastando-se das atividades de trabalho para a eficácia dos métodos gerenciais utilizados.

Progressivamente, vemos a configuração de um novo campo de saber/poder, as chamadas "ciências da gestão". Podemos dizer que esse novo campo se organiza em torno da ideia de que investir na gerência (agora chamada de gestão) como ciência seria primordial para resultados com maior probabilidade de sucesso. Observa-se desde então o emprego consideravelmente profuso do termo gestão: de recursos, de pessoas, das finanças pessoais, do capital humano, do estresse, por exemplo.

O termo, entretanto, é em geral utilizado como sinônimo de administração ou gerência. Esse uso, que parece apontar a supervalorização da administração supostamente científica e especializada, costuma deixar de enfatizar uma importante peculiaridade da noção de gestão - no sentido de (re)normatização, retrabalho sobre as normas antecedentes -, a de que há sempre uma dimensão de gestão nas atividades humanas, incluídas aquelas tidas como pura repetição.

As infidelidades e suas diversas combinações fazem com que algo sempre escape à tentativa de objetivação, de identificação completa de tudo que compõe o ambiente de trabalho. O humano para viver e trabalhar busca recriar o meio, produzir novas normas e, ao renormatizar, faz aumentar a variabilidade:

Todos os tipos de infidelidades se combinam, se acumulam, se reforçam uma na outra, no conjunto de um ambiente cultural. Isso faz com que nunca se possa listar totalmente, de maneira exaustiva, um ambiente de trabalho. (SCHWARTZ; DURRIVE, 2007, p. 191)

Tais infidelidades demandam ser geridas, como uso de si, o que envolve negociações, negociações de negociações, enfim, dramáticas gestionárias. Schwartz e Durrive (2007) falam em uso de si por si (compromissos microgestonários) e por outros (normas, procedimentos).

Todo o trabalho envolve, portanto, gestão, usos de si, ou seja, estabelece-se uma perspectiva diferenciada, quando se entende que nunca há simples execução, mas antes, uso, a convocação de colocar em ação e desenvolver capacidades mais amplas do que as enumeradas pela tarefa prescrita. Trabalhar coloca em tensão o uso de si requerido pelos outros e o uso de si consentido e comprometido por si mesmo (DURRIVE; SCHWARTZ, 2008).

\section{O debate clandestino tornado público sob a mediação de um compromisso ético}

Uma pergunta que logo surge quando apresentamos algumas dessas ideias em um campo cujo objetivo central é prevenir doenças e acidentes de trabalho (acidentes esses que, muitas vezes, podem ser fatais, sendo a disciplina operacional um dos grandes objetivos anunciados nas campanhas) é a seguinte: aonde se quer chegar com essas reflexões? Como se trazem essas reflexões para as práticas concretas em SST? 
Uma análise precipitada poderia entender as reflexões levantadas como uma apologia do laissez-faire ou do fim da obediência às normas prescritas (que são tão caras, tratando-se de segurança industrial, especialmente em atividades que envolvem notório perigo), mas o que se pretende afirmar junto com os autores evocados é que viver/trabalhar sempre estabelecerá um debate de normas que, dependendo da situação, pode ser interno, clandestino ou público. As linhas argumentativas que apresentamos apostam na fertilidade desta última opção.

Retirar os debates da clandestinidade torna-se vital para a saúde e segurança dos trabalhadores, em especial para que as responsabilidades e consequências da clandestinidade não sejam assumidas individualmente. Alguns autores citados ressaltam que o favorecimento dos espaços para trocas, diálogos e debates sobre o trabalho é especialmente benéfico para a produção de conhecimentos, desenvolvimento das atividades e dos "saberes-fazer de prudência", expressão utilizada por Cru e Dejours (1983) para os procedimentos inventados, desenvolvidos e compartilhados pelos trabalhadores que não são adquiridos em treinamentos formais, mas no curso da própria atividade e se encontram patrimonializados e disponibilizados nos saberes de ofício.

Voltando mais uma vez a Dejours (1995), lembramos que algumas condições/situações podem favorecer ou dificultar a mobilização da inteligência criativa, destacando-se três condições básicas para essa mobilização: 1. a existência de uma organização prescrita do trabalho - as regras do jogo; 2. a transparência - para que os riscos pelas transgressões da prescrição não sejam assumidos clandestinamente pelos trabalhadores; 3 . o reconhecimento do trabalho realizado.

Quanto à dinâmica do reconhecimento, o autor aponta dois tipos de julgamento: o de utilidade e o de beleza. O julgamento da utilidade técnica, social ou econômica não se restringe à recompensa, pois também diz respeito à dimensão simbólica. É geralmente realizado pela hierarquia ou clientes. Já o julgamento de beleza ou estético é realizado por quem conhece as regras de trabalho, geralmente os pares. Esse julgamento está relacionado à identificação ou, melhor dizendo, ao pertencimento do trabalhador a uma comunidade ou coletivo. Uma das soluções apontadas é a visibilidade, a divulgação dos achados técnicos, para que sejam julgados e reconhecidos pelo outro. A ocorrência dessa dinâmica demanda que sejam estabelecidas relações de confiança entre os envolvidos; assim, uma dimensão ética está fundamentalmente implicada. Nesse processo torna-se essencial a participação de trabalhadores e dirigentes na construção do espaço público interno de negociações.
Lembramos três proposições básicas sobre os laços de confiança. Primeiro, eles têm papel central na coordenação e cooperação, ingredientes necessários à saúde, segurança e ao desenvolvimento das atividades de trabalho de modo geral. Um segundo aspecto é que se trata de componente da saúde mental dos trabalhadores. Por fim, constituem construção intrinsecamente relacionada com a dimensão tempo, pois dizem respeito à congruência no tempo entre uma palavra dada e o comportamento que lhe é consequente.

Além dos aspectos de proteção à saúde e à produtividade, a cooperação vem sendo destacada por alguns autores como elemento fundamental para a segurança e confiabilidade dos sistemas sociotécnicos. Figueiredo e Athayde (2004) abordam o papel estratégico da cooperação na formação dos coletivos de trabalho. A dimensão coletiva do trabalho é explorada para pensar segurança e confiabilidade nos sistemas complexos de produção petrolífera offshore.

\section{Considerações finais}

A tradicional abordagem dos riscos parte da identificação dos elementos suscetíveis de provocar, em determinadas circunstâncias, danos à saúde - esses perigosos elementos são denominados fatores de risco. A partir dessa identificação, produz ou mobiliza conhecimentos sobre esses fatores, para implementar medidas visando impedir que o risco se transforme em perigo. Os riscos geralmente são técnicos e materiais. Grande parte das medidas e dispositivos de prevenção envolve o fornecimento de meios de proteção para os trabalhadores. Tais abordagens certamente melhoram as condições de trabalho, mas só são possíveis para os fatores de risco que podem ser objetivados, que são objeto de conhecimento relativamente estabilizado. Com relação aos fatores procedentes da atividade e aos chamados fatores humanos, entretanto, elas se demonstram limitadas.

Este tipo de fator, marcado por forte dimensão de
subjetividade, não é identificável por objetivação sem
que coisifiquemos aquilo que não é uma coisa. Isso
acarretaria problemas não apenas éticos, mas tam-
bém de pertinência quanto à identificação dos fatores
de risco, pois desnaturando os fatores humanos no
momento da identificação, será identificado neces-
sariamente algo diferente daquilo que de fato existe.
(NOUROUDINE, 2004, p. 41, grifo dos autores)

As abordagens objetivas do risco negativo, portanto, resolvem apenas parte dos problemas e ignoram seus aspectos não estabilizados e imanentes. $\mathrm{O}$ autor aponta a necessidade de definições de formas organizacionais que possam favorecer a capacidade de gestão dos protagonistas do trabalho no curso da atividade, em abordagem ascendente da prevenção 
que contemplaria e destacaria os saberes-fazer de prudência, constitutivos dos ofícios e da cultura de segurança que lhes é inerente.

A realização do trabalho, no sentido de atividade humana, supõe engajamento corporal, cognitivo e é atravessada pelo risco. A análise dos riscos acarreta a busca de meios para favorecer sua gestão, ou seja, pressupõe considerá-los positivamente. O risco abordado via experiência na análise de risco "implica dar espaço, nas estratégias de prevenção, a avaliações, julgamentos, tentativas de correção etc. efetuados em tempo real no curso da atividade" (NOUROUDINE, 2004, p. 57).

Para avançarmos na direção de outras possibilidades de abordagem dos riscos ocupacionais, para além da dimensão prescritivo-normativa, entendemos serem fundamentais o reconhecimento e a ampliação da capacidade de análise e gestão coletiva sobre o próprio trabalho.

As soluções possíveis para esse aspecto do problema estão por ser buscadas não num aumento de regulamentação e de meios de proteção (necessários para certos tipos de risco), mas na definição de formas organizacionais que seriam suscetíveis de favorecer a capacidade de gestão dos protagonistas do trabalho no curso da atividade. (NOUROUDINE, 2004, p. 42)

Uma importante questão que geralmente se coloca neste ponto é: qual seria a forma de instituir e manter essas/esses práticas/procedimentos/espaços como algo vivo? Inicialmente, talvez seja o caso de admitir que não existem garantias absolutas, pois não se trata da adoção de um novo modelo que, após adotado, funcionaria por si só ou de um estado a ser atingido. Assim, incluir "os aspectos psicossociais", as dimensões subjetivas, o ainda "sem forma" na tradicional "gestão dos riscos" no trabalho talvez sinalize a necessidade de admitir e sustentar um determinado tempo e transitar em zona de indeterminação.

Embora sem garantias, com os referenciais apresentados, podemos pensar alguns pontos norteadores. Vimos com Dejours (1995) que as práticas instauradas por determinadas gerências, quando desconsideram o papel estratégico da solidariedade e da cooperação, e a dimensão gestionária embutida nas atividades, podem produzir danos à saúde e à confiabilidade. Esses danos podem manifestar-se sob a forma de patologia, de acidente de trabalho, ou, ainda, assumir formas menos precisas, como a apatia ou algum mal-estar indefinido, e assim afetar a produtividade e a qualidade dos produtos ou serviços prestados. A mobilização/desenvolvimento da capacidade criativa e do patrimônio individual e coletivo dos trabalhadores, que inclui os saberes-fazer de prudência (CRU; DEJOURS, 1983), podem ou não ser favorecidos por algumas formas organizacionais mais ou menos participativas.
A dimensão normativa foi evocada aqui para lembrar que a variabilidade é inerente ao humano, às situações de trabalho e à vida. Assim, a todo instante, somos convocados a gerir, fazer escolhas, ressignificar e retrabalhar as normas. Essas ideias são incompatíveis com as que se mantêm reforçando a ideia de que seguir fielmente os procedimentos e prescrições bem feitas seria o suficiente para garantir a segurança ou a saúde.

Os autores apresentados apostam nas perspectivas de um reposicionamento dos trabalhadores para que eles assumam o protagonismo nas análises e gestão do trabalho, da saúde, dos riscos, das intervenções e produção de conhecimento em SST. Destacam, portanto, a relevância de reorientação que se volte para a premissa de aproximação do trabalho real, das situações concretas, para a atividade, que tem intrinsecamente a capacidade de convocar e integrar as dimensões que costumam ser separadas pela administração e organização do trabalho no mundo capitalista. A partir desse reposicionamento podemos repensar qualidade, gestão de riscos, produtividade, promoção da saúde e segurança de forma mais efetiva, abrangente e integrada.

Segundo Vasconcelos e Lacomblez (2004, p. 163), esse caminho começa a ser vislumbrado no contexto europeu com a Diretiva-Quadro 391/89/CEE. Essa norma propõe como ponto de partida a análise prévia, contextualizada e recorrente das situações de trabalho enfatizando a relação entre os processos de trabalho e a saúde, e garante aos trabalhadores, como obrigação de seus empregadores, sua consulta e participação em todas as questões relativas à segurança e à saúde no local de trabalho. Vasconcelos (2008) destaca ainda dois aspectos cruciais para afirmar essa nova direção. Primeiro lugar o foco da prevenção dos riscos deveria ser deslocado dos acidentes para o trabalho e sua organização. Em segundo, a participação dos trabalhadores deveria ser efetiva e não pontual, desde os projetos de concepção até a elaboração dos planos de prevenção. Assim seria possível a promoção do que denomina por "abordagem compreensiva da prevenção" (VASCONCELOS, 2008, p. 200). Nessa linha, a prevenção deveria atentar para o trabalho real; não apenas para o que não deu certo, mas também para o que obteve êxito.

Por fim, conforme procurou-se apresentar, alguns riscos podem estar relacionados até com as tentativas de simplificação da complexidade das atividades. As generalizações têm como premissa e consequência a redução da complexidade e a variabilidade da vida e do humano. As fórmulas genéricas que partem de simplificações jamais serão capazes de contemplar todas as variações e possibilidades de manifestações da vida e do humano. Sendo assim, cabe lembrar que nem todos os acontecimentos e riscos podem ser antecipados, controlados ou eliminados, seja no âmbito do trabalho ou da existência. 
As estratégias centradas exclusivamente na busca de garantia do cumprimento fiel das orientações, através da almejada disciplina operacional, podem e devem ser ampliadas com a inclusão e o destaque de outros aspectos também relevantes para a saúde e a segurança no trabalho, como o desenvolvimento de autonomia e de recursos (individuais e coletivos) para subsidiar as escolhas e a valorização do diálogo entre os saberes como exercício ético-político comprometido com valores de afirmação da vida - para além de uma perspectiva tecnicista.

\section{Contribuições de autoria}

Os autores participaram igualmente da elaboração e revisão crítica do texto e assumem a responsabilidade pública pelo seu conteúdo.

\section{Referências}

BENDASSOLLI, P.; SOBOLL, L. Clínicas do trabalho. São Paulo: Atlas, 2011.

BRASIL. Ministério do Trabalho e Emprego. Normas regulamentadoras de segurança e saúde do trabalho. NR-33 - Segurança e saúde nos trabalhos em espaços confinados. Brasília, DF: MTE, 2006. Disponível em: < http://portal.mte.gov.br/data/files/ FF8080812BE914E6012BF2FE9B8C247D/nr_33.pdf>. Acesso em: 01 jun. 2012.

BRITO, J. Saúde do trabalhador: reflexões a partir da abordagem ergológica. In: FIGUEIREDO, M. et al. (Org.). Labirintos do trabalho: interrogações e olhares sobre o trabalho vivo. Rio de Janeiro: DP\&A, 2004, p.161-187.

BRITO. J. C. Trabalho prescrito e trabalho real. In: PEREIRA, I. B.; LIMA, J. C. F. (Org.). Dicionário da educação profissional em saúde. Fundação Oswaldo Cruz. Escola Politécnica em Saúde Joaquim Venâncio, Rio de Janeiro: FIOCRUZ/EPSJV, 2009. Disponível em: <http:/www.epsjv.fiocruz.br/dicionario/verbetes/ trarea.html>. Acesso em: 7 jul. 2011.

CANGUILHEM, G. O normal e o patológico. 3. ed. rev. ampl. Rio de Janeiro: Forense Universitária, 1990.

CAPONI, S. A saúde como abertura ao risco. In: CZERINA, D. Promoção da saúde: conceitos, reflexões, tendência. Rio de Janeiro: FIOCRUZ, 2003, p. 55-77.

CHANLAT, J. F. Modos de gestão, saúde e segurança no trabalho. In: DAVEL, E. VASCONCELLOS, J. "Recursos humanos” e subjetividade. Petrópolis: Vozes, 2002, p. 118-128.

CLOT, I. A função psicológica do trabalho. Petrópolis: Vozes, 2006.

CRU, D.; DEJOURS, C. Les savoir-faire de prudence dans les métiers du bâtiment. Nouvelles contributions de la phychopatologie du travail à l'étude de la prévention. Les Cahiers Médico-Sociaux, Genebra, v. 27, n. 3, p. 239-247, 1983, .
DANIELLOU, F. (Org.) A ergonomia em busca de seus princípios: debates epistemológicos. São Paulo: Edgard Blücher, 2004.

DEJOURS, C. Inteligência operária e organização do trabalho: a propósito do modelo japonês de produção. In: HIRATA, H. (Org.). Sobre o 'modelo' japonês. São Paulo: EDUSP, 1995.

. A avaliação do trabalho submetida à prova do real: crítica aos fundamentos da avaliação. In: SZNELWAR, L.; MASCIA, F. L. (Org.). Trabalho, tecnologia e organização. São Paulo: Edgard Blücher, 2008. (Cadernos de TTO, 2).

DURRIVE, L.; SCHWARTZ, Y. Glossário da ergologia. Laboreal, Porto, v. 4, n. 1, p. 23-28, 2008.

FIGUEIREDO, M.; ATHAYDE, M. Coletivos de trabalho e componentes subjetivos da confiabilidade em sistema sociotécnicos complexos: considerações a partir da situação de trabalho em mergulho profundo na Bacia de Campos, RJ. In: FIGUEIREDO, M. et al. (Org.). Labirintos do trabalho: interrogações e olhares sobre o trabalho vivo. Rio de Janeiro: DP\&A, 2004, p. 241-275.

GLINA, D. Modelos teóricos de estresse e estresse no trabalho e repercussões na saúde do trabalhador. In: GLINA, D.; ROCHA, L. E. (Org.). Saúde mental no trabalho: da teoria à prática. São Paulo: Roca, 2010. p. 3-30.

INSTITUTO NACIONAL DO SEGURO SOCIAL. Norma Técnica sobre Lesões por Esforços Repetitivos ou Distúrbios Osteomusculares Relacionados ao Trabalho. Instrução Normativa INSS/DC, n. 98 de 05 dez. 2003. Disponível em: <http://www81.dataprev. gov.br/sislex/paginas/38/inss-dc/2003/98.htm >. Acesso em: 7 jul. 2011.

MAGGI, B. Bem-estar. Laboreal, Porto, v. 2,n. 1, p. 6263, 2006. Disponível em: <http://laboreal.up.pt/media/ artigos/54/maggi_v2n1_pt_1.pdf $>$ Acesso em: 7 jul. 2011. 
MENDES, R.; DIAS, E. C. Da medicina do trabalho à saúde do trabalhador. Revista de Saúde Pública, São Paulo, v. 25, n. 5, out. 1991. Disponível em: <http:/www.scielo.br/scielo.php?script =sci arttext\&pid =S0034-89101991000500003\&lng =en\&nr $\mathrm{m}=\mathrm{iso}>$. Acesso em: 30 jun. 2011.

NOUROUDINE, A. Risco e atividades humanas: acerca da possível positividade aí presente. In: FIGUEIREDO, M. et al. (Org.). Labirintos do trabalho: interrogações e olhares sobre o trabalho vivo. Rio de Janeiro: DP\&A, 2004. p. 37-62.

\section{ORGANIZAÇÃO INTERNACIONAL DO TRABALHO.} Riesgos emergentes y nuevos modelos de prevención en un mundo de trabajo en transformación. 2010. Disponível em:< http://www.ilo.org/wcmsp5/groups/ public/---ed_protect/---protrav/---safework/documents/ publication/wcms_124341.pdf $>$. Acesso em: 7 jul. 2011.

RODRIGUES, H. Quando Clio encontra Psyché: pistas para um (des)caminho formativo. Cadernos Transdisciplinares, Rio de Janeiro, v. 1, n. 1, p. 33-69, 1998.

SANTOS, B. S. Para um novo senso comum: a ciência, o direito e a política na transição paradigmática. 3. ed. São Paulo: Cortez, 2001.

. Trabalho e gestão: níveis, critérios, instâncias. In: FIGUEIREDO, M. et al. (Org.). Labirintos do trabalho: interrogações e olhares sobre o trabalho vivo. Rio de Janeiro: DP\&A, 2004, p. 23-33.

SCHWARTZ, Y.; DURRIVE. (Org.). Trabalho e ergologia: conversas sobre atividade humana. Niterói: Eduff, 2007.

TELES, A. L.; ALVAREZ, D. Interfaces ergonomiaergologia: uma discussão sobre trabalho prescrito e normas antecedentes. In: FIGUEIREDO, M. et al. (Org.). Labirintos do trabalho: interrogações e olhares sobre o trabalho vivo. Rio de Janeiro: DP\&A, 2004, p.63-90.

VASCONCELOS, R. J. S. D. O papel do psicólogo do trabalho e a tripolaridade dinâmica dos processos de transformação: contributo para a promoção da segurança e saúde no trabalho. 2008. 365 f. Tese (Doutorado em Psicologia)-Faculdade de Psicologia e de Ciências da Educação, Universidade do Porto, 2008.

VASCONCELOS, R.; LACOMBLEZ, M. Entre a autoanálise do trabalho e o trabalho de auto-análise: desenvolvimento para a psicologia do trabalho a partir da promoção da segurança e saúde no trabalho. In: FIGUEIREDO, M. et al. (Org.). Labirintos do trabalho: interrogações e olhares sobre o trabalho vivo. Rio de Janeiro: DP\&A, 2004, p. 161-187.

WISNER, A. A inteligência no trabalho: textos selecionados de ergonomia. São Paulo: Fundacentro, 1994. 